\title{
Construction of an Interdisciplinary Innovative Teaching Model - an Example of Digital Village and Interactive e-book in MingDao University
}

\author{
Wang shu-Huei \\ MingDao University Digital Design Dep. \\ Wen-Hua Rd, 52345, \\ ChangHua, Taiwan \\ angelawang36@gmail.com
}

\begin{abstract}
The interdisciplinary innovative teaching model for smart agricultural creation was jointly established by four universities in Taiwan, including National Yunlin University of Science and Technology, National Changhua University of Education, National Chiayi University and Mingdao University. The objective was to integrate curriculums of different fields in an innovative way, to conduct field practice and start-up incubation and to develop students' diversified interdisciplinary abilities. The specialty introduction program model was aimed at junior students for advanced study in the Department of Digital Design of Mingdao University. Students were trained with cultural and creative design ideas of interaction and integration so that their visions might be broadened to cope with the field of technological digitalization in the future and become type $\mathrm{T}$ talents of the program.
\end{abstract}

Key words: Interdisciplinary innovative teaching model, innovation methodology, interactive e-book design.

\section{Introduction}

Beichen communities in Tienwei nearby Mingdao University would be served as the experiment field. Students could have an in-depth understanding of local culture and develop innovative thoughts for a rural village. This interdisciplinary team was based on the interdisciplinary program model to develop students to have local agricultural community thinking and make good use of technology for field improvement. Operation of the program model was based on the Double Diamond Design Process, 4Ds for short, presented by the UK Design Council. This innovation methodology means to discover, to define, to develop and to deliver. Information and Communication Technology (ICT) would be incorporated to cope with burgeoning network, information and communication development. Accordingly, a specialty introduction program model for digital villages and interactive e-books was established. Local cultural characteristics were recorded and built. Design material was from local culture and digital techniques were applied for editing and production of the interactive e-book. Students were trained to use real material to produce audiovisual products, micro films and interactive e-books.

\section{Methodology}

The Double Diamond Design Process, 4Ds for short, was adopted for the research. Eighteen weeks of classes in a semester were divided into four phases and this innovative design process could help students to learn in a diversified manner. Meanwhile, the target was aimed at real fields so that the problems of the real world might be understood and design solutions could be presented. Upon the end of the classes, works were finished and shared with the local residents.

\section{Research method}

The Design Council of the UK proposed the Double Diamond Design Process (4Ds) in 2005, which started with divergent thinking and ended by convergent thinking represented by a diamond shape. This innovative method can be divided into four distinct phases - Discover, Define, Develop and Deliver. In the first diamond, the problem definition is confirmed for prototype production and the main purpose is to understand and locate the right problem. In the second diamond, the solution to solve the problem is created and the major object is to find out the right answer. See the figure.

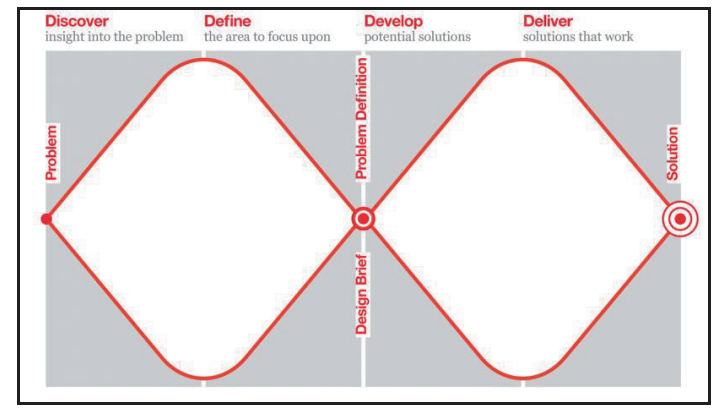

Fig. 1: 4Ds Double Diamond Design Process (British Design Council, 2005)

\section{Research structure and issue of field}

1) research structure: the research was based on $4 \mathrm{Ds}$ and the field under study was targeted at Beizhen Community and Nanzhen Community in Tienwei Township, Changhua County, Taiwan. There were eighteen weeks of classes and every four weeks were one unit. Discovery of the field started from week 1 to week 4 for cultural understanding and findings. Definition of the field began in week 4 thru week 8 for cultural experience and definition. Interdisciplinary workshops began in the $9^{\text {th }}$ week. The phase of development was from week 10 to week 13 for co-constructing and co-creating. Creative production was delivered from week 14 thru week 17 and the final results were exhibited in the $18^{\text {th }}$ week. Details of the structure are as follows: In the first phase of cultural understanding and discovery, students were asked to collect relevant cultural information in advance, investigate insufficient data related to the rural community and visit and discover problems of the field in person. For the second phase of cultural experience and definition, students discussed and defined problems of the community after visiting and experiencing it. In the third phase of co-construction and co-creation, sticky notes were used for students to discuss and solve problems. The cultural content of 
the community was constructed by item and innovation and technology were incorporated into media. On the final stage of creative production, products of different topics were created by groups, including the CIS e-book of Beizhen Community, e-book and action figure of Sanshan King, introduction e-book of Beizhen and Nanzhen Communities and e-book of visiting Beizhen Community. The accomplishments were displayed

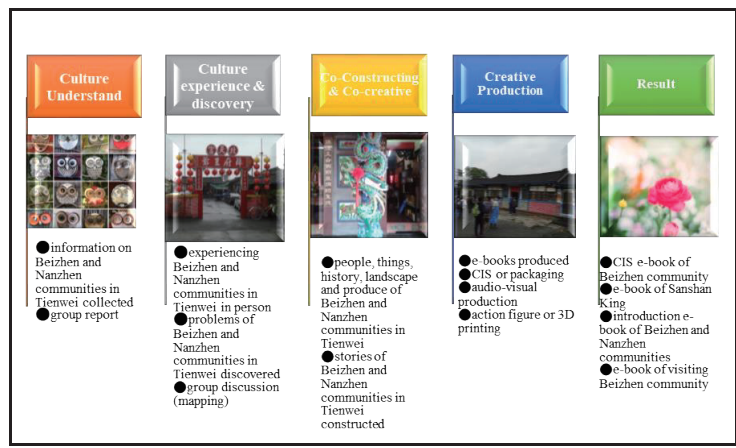

Fig.2: Research Structure and Steps

finally.

2) Issue of field: Students concluded ten problems of the communities via personal observing and experiencing, interviews and surveys. Students were also divided into four groups to choose solutions and works to the problems, which were as follows: (A).To re-plan and develop vacant land. (B). To enhance industrial competitiveness and increase employment of the youth. (C). How to retain young people. (D). How to preserve and protect historic spots. (E). How to extend industrial development. (F). Handicapped friendly accommodations not satisfactory. (G). No clear guidepost. (H). No significant image walls. (I). Scarce online information on the communities. (J). To add creative ideas to the characteristics of the communities and promote.

Interdisciplinary creative teaching model

Donald Norman mentioned in his book, Emotional Design, that creation should be based on emotional exchanges between people and objects. In this course, cultural feelings were emphasized and childhood memories were aroused so that creation based on interaction between people and objects could be presented through cultural experiencing, technological innovation, co-constructing and co-creating. This course of interdisciplinary teaching mainly consisted of the theories and techniques of four dimensions, including culture, technology, creation and design. Information related to culture was

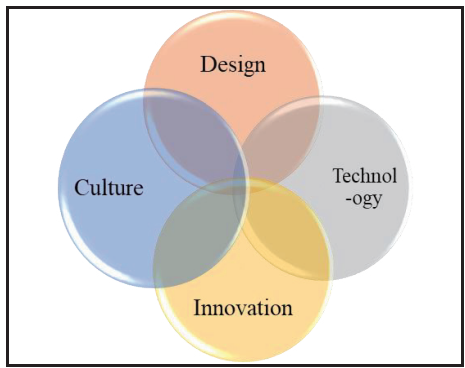

Fig. 3: Integrated Illustration of Interdisciplinary Teaching collected and understood and culture oriented design elements were added. Besides site surveys and personal interviews, ICT was incorporated to interactive e-books. Consequently, the final results might be displayed on the internet for real application.

\section{Interdisciplinary creative teaching}

OpenCourseWare, an innovative teaching approach presented by MIT in 2002, made people around the world share knowledge freely. IDEO founded D-School at Stanford, which was also an approach to innovative teaching. The Ministry of Education has been active in promoting creative teaching for the past few years. Colleges and universities, standing in the breach needed to cope with this global trend. First, teachers should develop a creative spirit in thinking (Shih-chung Chang, 2002; Wen-chi Luo, 2001). Tien-yu Lin also indicated in 2000 that education was the main force to motivate creativity. In other words, how to motivate students to develop their creativity is a critical key when teachers design their teaching. Chih-lang Tseng (2001) in his topic report, Teachers' Expertise Growth and New Missions, in a central memorial to the Great Teacher, Confucius, specified that not only renewal of curriculum, but also teaching innovation and conceptual breakthrough were required for educational reformation. Chia-cheng Yu (2003), a scholar, deemed creative teaching or teaching innovation referred to a new and unprecedented teaching approach or strategy that was different from tradition. The main goal of creative teaching is to enhance learning motive and motivate active learning of students to realize effective teaching and learning.

The D-School at Stanford helped people across different fields brainstorm among themselves through creative design procedures. How to incorporate innovative ideas into teaching methods, targets and accomplishments for students to learn in a diversified manner is something we need to work on.

\section{Innovative design process}

The innovative design process of IDEO, Deep Dive, was specially reported by ABC News Nightline in 1999. IDEO was asked to re-design something common within five days. Therefore, IDEO implemented a innovative design procedure to re-design a supermarket cart and the major steps included: 1 . perspective - to learn from the lives of others; 2 . observation to see things people don't do and listen to things people don't speak; 3. empathy - to put oneself in others' position; 4. brainstorming - to provide thoughts and excavate various possibilities from different fields; 5. prototype design - to produce the prototype and get feedback from the manager of the supermarket and consumers; and 6. practice - to modify the prototype to become a practicable product at the real field. David Kelly founded the D-school at the Stanford University to promote the creative design program and extend the practical method of creative design thinking to the academic circle. Establishment of the design procedure was based on integrated approaches for analysis, which helped designers to reduce their doubts about something they wanted to know (Chien-cheng Chang, 1995). Operation of the creative design process can get more people involved and develop something new and innovative that can't be imagined. Thus, application of the creative design process to interdisciplinary creative teaching can generate more creative ideas.

\section{Cultural and experiential learning}




\section{Recent Developments on Information and Communication Technology (ICT) Engineering- Meen, Yang \& Zhao ISBN: 978-981-14-2136-5}

Experiential learning referred to a process that one person built knowledge, obtained skills and enhanced self-value by experiencing directly (AEE, 1995). Besides, learning by doing of John Dewey, the theory of cognitive development presented by Jean Piaget, a cognitive psychologist, and the experiential learning cycle of Kurt Lewin, a social psychologist, also shared similar thinking. In other words, learners can have a deeper cognition about a certain culture thru direct experiencing and learning. A direct experience is stressed. The learning process started with specific activities, which provided a direct learning experience to learners; i.e., learning by doing emphasized by Dewey (Miao-kui Yen, 2001).

\section{Program modules of digital rural villages and} interactive e-books

1). program planning: the multimedia design (2) in the second semester of 2015 was the basis to develop the program modules for digital rural villages and interactive e-books. The Double Diamond Design Process, 4Ds for short, was adopted to divide eighteen weeks of classes into four phases. Four major steps included discovering, defining, developing and delivering. The contents of the course imparted for 18 weeks were illustrated as the figure and the program modules for digital rural villages and interactive e-books were constructed by re-defining the four major steps. The first step was cultural understanding and discovery; the second step was cultural experience and definition; the third step was co-construction and co-creation and the last step was creative production. Workshops across fields started in the ninth week for students and teachers of different specialties to exchange and learn.

2). In the first week, the ways to implement the course was explained and students would learn the basic interface of Indesign from weeks 2 to 3 . Their homework was to collect the information on Beizhen and Nanzhen communities in Tienwei and students also needed to understand basic layout design and appreciate works. President Chiu would guide the students to a trip to Beizhen and Nanzhen communities in Tienwei in week 4 so that they might have an in-depth cultural experience and

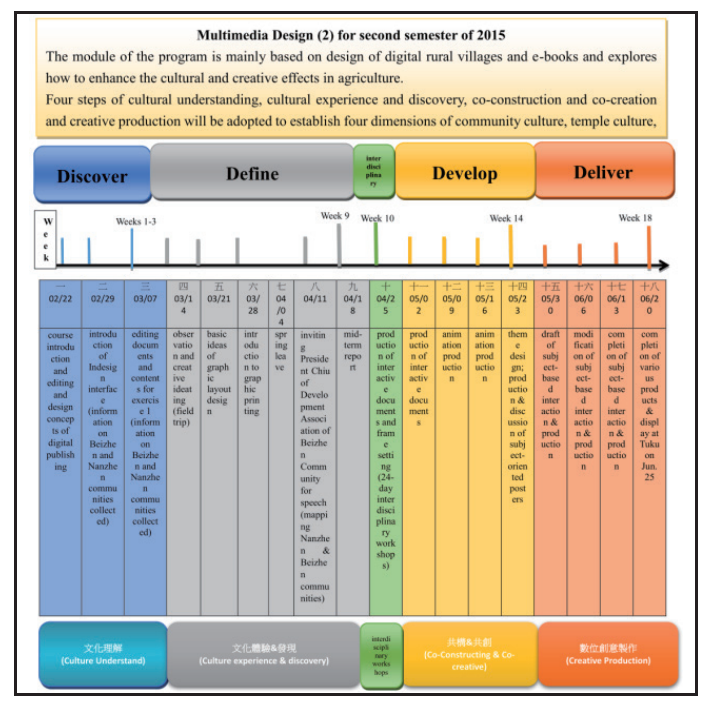

Fig. 4: Structure of Program Implementation discover problems. Meanwhile, personal observations could be shared at group discussions in the afternoon. Besides, teachers Huang and Chan from the local area would give DIY lessons. Fundamental skills on editing and printing would be instructed from weeks 5 thru 9. In week 8, President Chiu would be invited again to share culture, geography and history of Beizhen and Nanzhen communities and draw the local map with the students. A mid-term report on the information, cultural experience and findings of Beizhen and Nanzhen communities would be presented by students in week 9 . Problems discovered would be integrated with e-books. Specialty oriented teaching would be introduced from weeks 10 to 13 ; i.e., Indesign interaction and animation production. The direction and modification of the products would be discussed. Design execution and the outputs started from weeks 14 to 17. A final report and an exhibition of the results would be given in the $18^{\text {th }}$ week.

\section{Results and discussion}

This research was aimed at 16 juniors who pursued their further study at the Department of Digital Design in Ming Dao University. The name of the program was Multimedia Design (2) and Beizhen and Nanzhen communities in Tienwei were selected as the field for study. The problems of Beizhen and Nanzhen communities were found via cultural understanding and cultural experiencing and discovery. Students discussed the problems and set the direction of design that was short of in Beizhen and Nanzhen communities by co-constructing and co-creating. Four groups of e-books were concluded and related videos and products were also incorporated. Each group continued discussion and developed their ideas. For creative production, there were four interactive e-books, including Sanshan King of Zhenan Temple in Tienwei, cultural introduction of Beizhen and Nanzhen communities, CIS of Beizhen community, and let's visit Beizhen and Nanzhen communities described as follows.

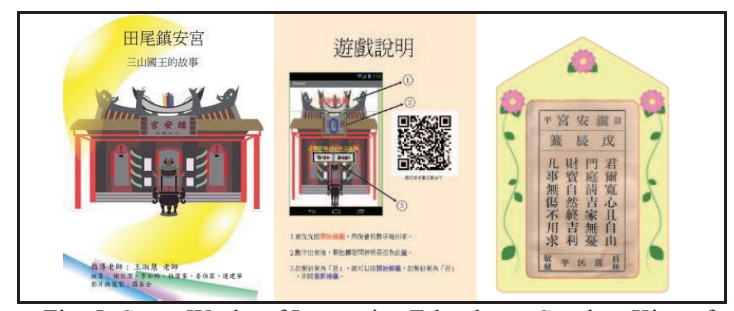

Fig. 5: Some Works of Interactive E-books on Sanshan King of Zhenan Temple in Tienwei

- Group 1: Sanshan King of Zhenan Temple in Tienwei field problems discovered: there were abundant cultural monuments, rich rural customs and friendly people in Beizhen and Nanzhen communities, but how to preserve them and help formation of a new industry to bring prosperity to the community were something to be considered. It was also found there were divine notes without an interpreter in Zhenan Temple.

design ideas for problem solving: in addition to lots of ancient houses, temples and historical spots, Zhenan Temple was the central belief for local people in Beizhen and Nanzhen communities. Diversified temple culture could be seen here, like the land deity temple, Beitien Temple of Lord Shueh, Chaoan Temple, Fuan Temple, Wuying General Temple, 
Zhenping Fute Temple and Shouan Temple, etc. Henceforth, the temple culture was focused and the story of Sanshan King of Zhenan Temple was explained. Modern simplicity was the tone of the interactive e-books to present Zhenan Temple and Lord Shueh Temple. Sanshan King was visualized by the action figure; QR code on the cellphone, interactive asking and interpreting the divine notes online motivated interaction with the local residents. More believers might be attracted to visit Beizhen and Nanzhen communities through interactive e-books, videos and animation and a creative temple culture industry could be developed to vivify the area.

\section{- Group 2: cultural introduction of Beizhen and Nanzhen communities}

field problems discovered: scarce online information about the communities was available and people who were interested couldn't get to know them.

design ideas for problem solving: the local cultural characteristics were emphasized in design to solve the problem of scarce information on Beizhen and Nanzhen communities. People, things, places, landscape and products were introduced via interactive e-books, videos and animation. As Beizhen community was famous for growing $70 \%$ of fruit, flower and rice seedling, pictures of the seedling were arranged in the interactive e-book to interest the readers on the internet.

\section{- Group 3: CIS of Beizhen Community}

field problems discovered: the biggest problems were no complete guidepost, historic information not arranged and the overall community not planned. If creativity was added to the community features and propagation was made, an ideal community would be born

design ideas for problem solving: CIS was designed for the residents of Beizhen community. It was expected the environment and visual effect could be integrated from basic to application systems so as to represent the local characteristics of Beizhen community. An interactive e-book was the main tool in combination with audiovisual and animation to propagate the CIS manual of the community online.

Finally, the works of the students would be shared with the residents of Beizhen and Nanzhen communities. Thirty-two people concentrated on watching the videos and e-books excitedly, gave compliments and made reservations for next gathering. A good relationship with Beizhen community had been maintained since 2015 and a cultural tour to Beizhen community in Tienwei would be made almost every semester. See the figure.

\section{Conclusion and review}

This program had been implemented for a semester and things to be completed were many. As students who participated in this course were pursuing further study, not all of them could show up on the weekend to take part in every activity. Lessons on the weekend too many times would be rejected. More time was required for students to understand ICT to produce creative ICT works. It was believed longer time would render to better and more complete works. Finished e-books were shared with community residents at the final activity and they were extremely pleased to see themselves in our recorded results expecting more opportunities like this in the future instead of a stop.

For instance, we expected to interpret about 60 divine notes thru the interpretation application, set up a guide map on the cloud or a website, place e-books and related information on the webpage to motivate propagation and browse. Furthermore, resource investigations of the cultural monuments in the community were worthy like the well maintained Fuchien style buildings and ancient three-section compounds of the Hsus, Chans and Changs. More interviews and surveys could be made if sufficient time was given, so follow-up endeavors were required. Besides, an overall connection could be made by the program in the following semester. We expected to take pictures from the air to construct a more complete outline of Beizhen and Nanzhen communities and believed it would be a booster to local and industrial progress.

\section{References}

[1]Chia-cheng Yu, Design and Assessment of Creative Teaching Proposals - an Example of Integrating Subjects. Editorial of National Taiwan Ocean University. Theory and Practice of Creative Teaching. Taipei: Shita Books.2003, Pp.: 179-209.

[2] Chien-cheng Chang, Design Method. Taipei: Liu-ho Publishing. 1995.

[3] Chih-lang Tseng, Teachers' Expertise Growth and New Missions, a topic report in a central memorial to the Great Teacher, Confucius, 2001. Nov. 23, 2004. Web page from the Ministry of Education: http://www.edu.tw/EDU_WEB/EDU_MGT/SECRETARY/ EDU0835001/history-publicnews/90/9010/s-carry.htm?search

[4] Jones, J.C., Design Methods. Van Nostrand Reinhold, New York, 1992.

[5] Majaro, S., Managing Ideas for Profit. McGraw-Hill, Maidenhead, 1988.

[6] Miao-kui Yen, Theoretical Foundation and Implementation Strategy of Integrated Activity. Published in the symposium on Grade 1-9 Curriculum Learning Areas edited by Yung-sheng Ou and Mei-chih Chuang. March toward a New Age Curriculum (7). Taipei: Association for Research \& Development of Teaching Materials. 2001.

[7] Ming-hui Chang, Management Strategies and Implementation Measures of Refined Schools. Teachers' Corner, 128, 2004, pp.: 9-22.

[8] Norman, D., Emotional Design : Why we love(or hate) everyday things. New York: Basic Book, 2004.

[9] Scherer,K.R., On the nature and function of emotion: A component process approach. In K. R. Scherer \& P. Ekman(Eds), Approaches to emotion. Hillsdale, NJ:Erlbaum, 1984, pp.293-318

[10] Shih-chung Chang, Teaching Innovation - Application and Examples. Taipei: Pro-Ed Publishing, 2002.

[11] The AEE Horizon, Association for Experiential Education, AEE Definition of Experiential Education.1995, 15 ( 1) , 21

[12] Tien-yu Lin, Exploring Expertise Growth and Development of Educators from the Aspect of Knowledge Economy. School Administrators. 9, 2000, pp.: 24-27.

[13] Wen-chi Luo, Creative Thinking and Innovative Teaching. Hanlin WordPress. 25, 2001, pp.: 4-5.

[14] Design Council (2005). Eleven lessons- Managing design in eleven global brands: The design process. Retrieved January 07 , 2018 ,

from

http://www.designcouncil.org.uk/sites/default/files/asset/docume nt/ElevenLessons_Design_Council\%20\%282\%29.pdf

[15] d.school : http://dschool.stanford.edu

[16] Massachusetts Institute of Technology: Open Course Web Page http://www2.myoops.org/twocw/mit/

Acknowledgements The extended to the Ministry of Education for the subsidy provided to the Innovative Alliance Program for Smart Living in 2016 - Innovation Alliance for Smart Villages. 